\title{
Barriers to cervical screening in women who have experienced sexual abuse: an exploratory study
}

\author{
Louise Cadman, ${ }^{1}$ Jo Waller, ${ }^{2}$ Lesley Ashdown-Barr, ${ }^{3}$ Anne Szarewski ${ }^{4}$
}

\begin{abstract}
- Additional supplementary tables are published online only. To view these files please visit the journal online (http://dx.doi. org/10.1136/jprhc-2012100378)

${ }^{1}$ Research Nurse Consultant, Centre for Cancer Prevention, Wolfson Institute of Preventive Medicine, Queen Mary University of London, Bart's and the London School of Medicine, London, UK

${ }^{2}$ Senior Research Associate, Health Behaviour Research Centre, University College London, London, UK

${ }^{3}$ Research Nurse, Centre for Cancer Prevention, Wolfson Institute of Preventive Medicine, Queen Mary University of London, Bart's and the London School of Medicine, London, UK ${ }^{4}$ Clinical Senior Lecturer, Centre for Cancer Prevention, Wolfson Institute of Preventive Medicine, Queen Mary University of London, Bart's and the London School of Medicine, London, UK
\end{abstract}

\section{Correspondence to}

Dr Anne Szarewski, Centre for Cancer Prevention, Wolfson Institute of Preventive Medicine, Queen Mary University of London, Bart's and the London School of Medicine,

Charterhouse Square, London EC1M 6BQ, UK; a.szarewski@qmul.ac.uk online under the BMJ Journals unlocked scheme, see http:// ard.bmj.com/info/unlocked.dtl

\section{Abstract}

Objectives To explore self-reported cervical screening history and barriers to attendance among women who have been sexually abused and to identify measures to improve the experience of cervical screening for these women.

Methods Women visiting the website of the National Association for People Abused in Childhood (NAPAC), who had been sexually abused, were invited to complete a survey of their views and experiences of cervical screening. This included closed questions on demographic characteristics and cervical screening attendance, open questions on barriers to screening, and the opportunity to submit suggestions to improve this experience for women who have been sexually abused. Content analysis was used to code responses to the open questions. Four women also participated in a discussion group.

Results Overall, 135 women completed the closed questions and 124 provided open-ended responses. $77.5 \%$ of responding women who were eligible for cervical screening in England had ever attended, $48.5 \%$ at least once in the previous 5 years, but $42.1 \%$ of women aged 25-49 within 3 years. A total of nine higher order themes were identified related to barriers to screening, one related to intention to attend screening and five related to suggestions to improve screening.

Conclusions This study supports the idea that women who have experienced sexual abuse are less likely to attend for regular cervical screening, with under half screened in the last 5 years compared to the National Health Service Cervical Screening Programme figure of $78.6 \%$. Suggestions to improve the experience for abused women focused on communication, safety, trust and sharing control. Further research in this area is warranted to ensure that this at-risk population is appropriately served by cervical screening.

\section{Key message points}

A history of sexual abuse can be a barrier to attendance for cervical screening.

- Those who have been abused find it very difficult to disclose their abuse history.

- Sensitivity to the issues and allowing more time have been highlighted as areas where improvements could be made.

- Sharing control and support may empower women who have been sexually abused and ensure that they attend regularly for cervical screening.

\section{Introduction}

The National Health Service Cervical Screening Programme (NHSCSP) is a national, government-funded cervical screening programme using a call-recall system. It has been estimated that the NHSCSP saves up to 5000 lives per year. ${ }^{1}$ All women registered with a general practitioner (GP) in the UK are sent regular invitations for free cervical screening. The routine screening interval is 3 or 5 years, depending on age. The age at which women are first invited is either 20 or 25 years and ceases at 60 or 64 years, varying between the different countries of the UK. The majority of cervical cancer cases in the UK are in under-screened women. ${ }^{2}$ A recent audit of invasive cervical cancer in England confirmed that only $29 \%$ of these cancers occurred in those who had adhered to screening interval guidelines. ${ }^{3}$ Therefore non-attendance for cervical screening must be seen as a major risk factor for cervical cancer. The NHSCSP reported that on 31 March 2011, 78.6\% of eligible women had been screened at least once in the previous 5 years. ${ }^{4}$ This means that approximately one in five 
women had not been screened within the past 5 years and could be regarded as non-attenders.

Statistics on the prevalence of sexual abuse perpetrated against women and children vary widely ${ }^{5-9}$ but the most comprehensive UK data from the National Society for the Prevention of Cruelty to Children reported in 2000 that $21 \%$ of girls aged under 16 years experience sexual abuse. ${ }^{10}$ It has also been stated that almost one in five women will be the victim of sexual assault in their lifetime. However, only approximately $40 \%$ of rapes are reported and $31 \%$ of children who have experienced abuse reach adulthood without disclosing this, ${ }^{11}$ indicating that these estimates could be conservative.

Evidence suggests that there are higher levels of gynaecological problems and cervical neoplasia in women who have been abused than those who have not. ${ }^{12-18}$ Sexual abuse can reasonably be considered to put a woman at increased risk of cervical neoplasia. This may be attributable to a number of factors other than non-attendance for screening, including early exposure to high-risk human papillomavirus (HPV), the main risk factor for cervical cancer. ${ }^{19-22}$ In addition, it has been shown that women who have been sexually abused are more likely to engage in behaviours associated with health risk such as smoking, drug and alcohol misuse and high-risk sexual behaviour. ${ }^{23-25}$ There are many reported barriers to attendance for screening in the general population. These include practical obstacles such as time constraints and lack of childcare but also emotional and psychological barriers including embarrassment and fear of pain. ${ }^{26}{ }^{27}$ It has been suggested that among the non-attenders for screening are women who have been sexually abused. ${ }^{28-32}$ There are many potential responses to the trauma of sexual abuse. Some of the more damaging behavioural responses have already been outlined but reaction to the experience has been likened to post-traumatic stress disorder. ${ }^{32-34}$ One way of coping with the trauma of sexual abuse is to control or avoid the triggers of trauma responses. This may mean not attending for cervical screening.

Intimate gynaecological examinations can be particularly stressful for women who have been abused because of the parallels with the abuse situation, for example perceived loss of control, the power disparity and the physical sensation of the examination. ${ }^{33}{ }^{35} \mathrm{It}$ is not everyday practice for a clinician to ask directly about sexual abuse and many women find disclosing abuse difficult. ${ }^{33}$ There is little empirical evidence about the specific barriers to cervical screening in this hard-to-identify group of women, or about measures that might be taken to facilitate screening in this at-risk group.

This exploratory study was designed to use mixed methodology: an online survey followed by discussion groups, with the aims to:

- Explore self-reported cervical screening history among women who have been sexually abused;
- Explore barriers to attendance for cervical screening in a population of women who have experienced sexual abuse;

- Identify measures to improve the experience of screening for women who have been sexually abused.

It was hoped that by seeking this information directly from the women themselves the findings could be assimilated into the body of research on this topic and used to help to inform areas where future research could be directed, and in particular where clinicians could effect changes in their practice.

\section{Methods}

\section{Participants}

Women aged 20 years or older, visiting the website of the National Association for People Abused in Childhood (NAPAC), a British charity providing support and information for people who have been abused, were invited to complete a web-based survey of their views and experiences of cervical screening. NAPAC's e-mail service and online surveys suggest that people access the website, from the UK and outside, to explore web-based information that can then be a stepping stone to telephone or face-to-face support. For others, the complete anonymity of the service is important, with the absence of links to any identifying aspect of their lives.

Women in England are invited for their first cervical screening test as part of the NHSCSP at the age of 25 years. Women aged $20-24$ years were included in the study population as they would be invited for screening in the near future, and would already be eligible in Scotland and Wales. It was made clear that all responses would be treated in the strictest confidence.

At the end of the survey, women were asked to provide contact details if they would be willing to participate in a discussion group about cervical screening. These were stored separately from survey responses, which were coded and anonymised.

\section{Procedures}

A link to a short survey was uploaded onto the website of NAPAC. The survey included closed questions assessing demographic characteristics (age, English residency, relationship status and the age of leaving full-time education), screening history (if ever screened and approximately how long since their last test) and history of abuse. Participants were asked to indicate which kinds of abuse they had experienced: physical, sexual, emotional, neglect, ritual, spiritual or other. In order to elicit as wide a range of responses as possible, open questions were used to assess perceived barriers to screening participation (e.g. "If you haven't ever had a smear test, or you sometimes put off going when you are invited, please use the box below to write the main reasons for this.") and suggestions for improvements to the screening service 
("Can you think of anything that might make women who have been abused more likely to go for cervical screening? Please use the box below to tell us your ideas."). The wording of the questions was developed in collaboration with staff at NAPAC to ensure it was sensitive and acceptable to women visiting the website.

The planned qualitative phase of the research was hampered by women's understandable reluctance to take part in discussion groups on such a sensitive issue and the logistical challenges of women from all over the UK and beyond having completed the survey. Just one discussion group was convened, with four participants. Given that insufficient data were collected for stand-alone qualitative analysis, the discussion group was transcribed verbatim and quotations used to add depth to the data from the open-ended survey questions.

The study was approved by the University College London Research Ethics Committee and survey data were collected from 25 June to 31 October 2010. The discussion group took place in January 2011.

\section{Data analysis}

Statistical analyses, including Fisher's exact test, were performed using STATA 1C/11.

The survey open questions were reviewed by two authors and a coding frame for content analysis ${ }^{36}$ was developed with 15 higher order themes, divided into nine related to barriers to screening: self-worth; power disparity; trust, safety and disclosure; physical pain; sexual victimisation; mechanics of the examination; fear and anxiety; communication barriers; impact on coping strategies; one theme related to intention to attend screening; and five related to suggestions to improve the experience of screening for women who have been abused: disclosure; safety, trust, sharing control; communication; position, procedure, environment; time and space. Each higher order theme was comprised of sub-themes. There were 93 sub-themes (see online supplementary Table S1 at http://jfprhc.bmj. com/content/38/4/toc). The responses were coded independently by two authors. The mean interobserver agreement was $89.5 \%$ with a mean kappa $(\kappa)$ of 0.67 , which can be interpreted as substantial agreement. ${ }^{37}$ Where there was disagreement the coding was agreed by consensus.

\section{Results}

Of the 159 women who began completing the survey, one was aged under 20 (18 years) and 12 had no history of abuse and so were excluded from analyses. A further 22 participants who had experienced nonsexual abuse only, or had not entered any response into the open questions, were also excluded. This resulted in a final sample size for analysis of 124 for content analysis of open questions and 135 for the closed questions. Four of the survey participants took part in a discussion group. [NB. Throughout this article codes are used to denote whether an individual was a web survey participant $(\mathrm{Pt})$ or a discussion group participant (DPt).]

\section{Characteristics of the sample and cervical screening history}

The demographic characteristics of the sample are available elsewhere (see online supplementary Table S2 at http://jfprhc.bmj.com/content/38/4/toc). The age range of respondents was 20-59 years with a mean age of 34.5 (SD 9.25) years. Among women aged 25-64 years residing in England $(n=85), 77.5 \%$ had ever attended for screening, of whom $48.5 \%$ had been screened at least once in the previous 5 years. This group consisted of $60.5 \%$ of the women aged $25-49$ years and $33 \%$ of those aged 50 years or older. Only $42.1 \%$ of the women aged 25-49 years had been screened within 3 years in line with current UK recommendations (Table 1 ).

\section{Content analysis of open questions}

See online supplementary Table $\mathrm{S} 1$ at http://jfprhc. bmj.com/content/38/4/toc.

\section{Barriers to screening attendance}

Self-worth

Of the 124 women completing the open question on barriers, $23 \%(n=28)$ of participants made at least one comment related to their self-worth. Included are issues that have been reported in previous research including embarrassment and self-consciousness. ${ }^{27}$ There were also remarks more specific to women who have been abused such as concerns that they are "not physically normal" (Pt76) or "grotesque" (Pt124) and have "visible scarring" (Pt93) or "signs of abuse or trauma" (Pt9). They expressed feelings of "shame" (Pt27) and "guilt" (Pt14), that "abuse is your fault and you are dirty" (Pt88). There was even the idea that an abused woman's "sense of entitlement to good treatment has been taken away" (Pt66).

Table 1 England residents screening attendance by age group (English respondents only, $n=101$ )

\begin{tabular}{lcrrrr}
\hline \multicolumn{5}{c}{ Time since last screen (years) } \\
\cline { 2 - 6 } $\begin{array}{l}\text { Age } \\
\text { (years) }\end{array}$ & $<\mathbf{3}$ (\% of & $\mathbf{3}-\mathbf{5}$ & $\mathbf{>}$ & \multicolumn{1}{l}{ Never } \\
age group) & $\mathbf{( \% )}$ & $\mathbf{( \% )}$ & $\mathbf{( \% )}$ & Total \\
\hline $20-24$ & $5(31)$ & $1(6)$ & $1(6)$ & $9(56)$ & 16 \\
$25-49$ & $32(42)$ & $14(18)$ & $19(25)$ & $11(15)$ & 76 \\
$>49$ & $2(22)$ & $1(11)$ & $5(56)$ & $1(11)$ & 9 \\
Total & $39(39)$ & $16(16)$ & $25(25)$ & $21(21)$ & 101 \\
\hline
\end{tabular}


Power disparity

There is a clear power differential between the smear taker and the woman undergoing the test and 29\% $(n=36)$ made at least one comment related to this. They made remarks about feeling vulnerable, and someone having control over them being "similar to the control that is suffered during abuse" (Pt99). They also reported having "little choice over the test" (Pt124) - "it is not what I chose to do myself but what someone else is telling me I need to do" (Pt49). Some felt "hounded" (Pt18) to have it done with little control over the timing of letters or clinic waiting time. A phrase that was used by a number of women was "something is being done to you" and implicit in this is the lack of control that the woman feels. However, when a woman felt she had "allowed her [GP] to do it" (Pt41) she had been able to go through with the smear test.

Trust, safety and disclosure

Just over $20 \% \quad(n=26)$ of women's responses were coded as pertaining to trust, safety and disclosure. These were interlinked with women wanting to "trust that I will be safe" (Pt71). They questioned how they could trust a stranger or someone with whom they had not built a relationship. Women reported problems disclosing that they had been abused. Four women had responses related to loneliness or isolation and also how this might impact on disclosure: "too difficult to tell ... feel like nobody would understand" (Pt27). Five women raised the issue of the gender of the smear taker as a barrier to attendance for screening with the implication that they would "want a woman" (Pt 142). It should be noted however that one woman remarked that her abuser had been a woman and challenged "the assumption is that if a woman does the test that will make it OK" (Pt68).

Physical pain

Many women find cervical smear tests uncomfortable or even painful. In this sample, 21\% $(n=26)$ of respondents reported physical pain or tension. Understandably women who had ever attended screening were significantly more likely to report this (25 vs $1, p=0.041$ Fisher's exact test) (see online supplementary Table S3 at http://jfprhc.bmj.com/ content/38/4/toc). Seven women (6\%) reported being tense and unable to relax for the test making the experience particularly difficult. This was linked with not being able to disclose the cause of this tension (Pt148) and with avoiding the test (Pt124).

\section{Sexual victimisation}

Many responses included a comment that was coded under the higher order theme of sexual victimisation, $(38 \% ; n=47)$, with $15 \%(n=18)$ of respondents highlighting the parallels with their previous experiences, being "exactly like it used to happen when I was abused" (Pt66). Five women likened it to rape or violation with one going so far as to describe it as "legalised rape" (Pt18). They commented on the intrusive and invasive nature of the test and how they did not like to be "lying down exposed ... having somebody touch me in that area" (Pt100) or "having a stranger standing there" (Pt12).

Mechanics of the examination

The woman's position on her back during her smear test reminded some of the abuse situation "I hate being on my back while things are done to me" (Pt21). They noted difficulties with penetration (5\%) "part of the abuse was to force things inside me and this seems to be the same kind of thing" (Pt42). The environment and equipment used were also noted negatively.

Fear and anxiety

A third of women $(n=41)$ made at least one comment related to fear and anxiety. There was a statistically significant difference between women who had ever attended for cervical screening and those who had not $(p=0.009)$ with those who had attended being less likely to express fear and anxiety (see online supplementary Table S3). Most comments were linked with either a general fear or more specifically a fear of the test itself. Nine women were fearful of the effect of the test, that it might "trigger memories" (Pt25) or "re-traumatise" them or that they may be perceived by the smear taker in a certain way because of their response - "losing it and looking stupid" (Pt45). There was, however, also fear of the consequences of not doing the test and of cancer and that "past experiences may affect the results" (Pt31) or "I know I should get checked which is scary in itself but actually going for the test is far scarier" (Pt36).

Communication and knowledge

Lack of communication skills and sensitivity of the smear taker was mentioned by $17 \%(n=21)$ of the women. There was criticism of the lack of knowledge and understanding of the impact of abuse and the possible responses of a woman who has been abused such as dissociation and tearfulness which can result in a "panic response by the professional" (Pt49). Mention was made of the lack of information on the screening literature pertaining to abuse.

Impact on coping strategies

Coping with trauma can result in a number of responses. Many women $(40 \% ; n=49)$ referred to the effect on coping mechanisms such as dissociation, depression and self-harm, and triggering of these responses and memories which some "try to suppress" (Pt25) or avoid. Women reported having been once for their test but that the consequences of it led to avoidance: "I only went once ... after I had to selfharm quite seriously ... to help cope with the experience" (Pt36). 
Intention to attend screening

Six women reported that they did not intend ever to attend screening and $26(21 \%)$ said that they had been but would not go again or were putting off going. Two said that they would take a chance by not going and hope for the best. Four women felt that on balance the fear or risk of cervical cancer did not outweigh the fear of the test and said that they would "rather die of something that screening would pick up than be in that position again" (Pt12). Three women commented on their perceived risk of cervical cancer with one woman perceiving her risk to be low because she "does not have relationships" (Pt142).

\section{Improvement of cervical screening}

Disclosure

As previously mentioned, disclosing abuse can be difficult. The importance of practitioner continuity, with someone who knows of the abuse, was highlighted by eight women with a further six suggesting a general awareness and flagging of abuse in the medical notes. Two mentioned needing time to disclose. Some women felt that if the clinician took the initiative, with routine checking or asking directly, this may help - "when you are abused ... the right to speak up, the ability to speak up ... that is something that is taken away" (DPt4). A non-verbal means of communicating, such as a standard recognisable card indicating a history of abuse, was also suggested.

Safety, trust, sharing control and enabling

Almost half of the respondents $(46 \% ; n=57)$ made suggestions relating to safety, trust and sharing control. Much of this was around choice - of having a chaperone, being accompanied by someone, who would take the smear, or the gender of the smear taker. Women wanted to choose whether to go for screening and that if they could not go through with the procedure they wanted to be able to walk away and return another time without feeling "naughty", that they could have "trial runs". Women should be asked for their consent or "permission first" (Pt144) and be assured that if they gave an agreed signal, or if they said stop, the clinician would stop. Women need to be "respected" and to "trust" the doctor or nurse. Fourteen women (11\%) also wanted to be more directly involved in the procedure either by inserting the speculum themselves or doing their own smear with supervision. Some called for a self-test that they might do in the privacy of their own home.

\section{Communication}

Poor communication by health care staff was mentioned as a barrier to attendance. One participant described "ignorance, rough treatment, insensitivity ... joking, crudeness and shouting at [the] patient" (Pt49). Half the women (53\%) made a comment coded under the higher order theme of communication. The sensitivity, understanding and attitude of the smear taker were important factors identified by women as a way to improve the screening experience. Women highlighted the value of acknowledging the abuse and the difficulties that screening poses for abused women. They also suggested that having a special knowledge of abuse and coping responses and mechanisms such as grounding and distraction techniques could be useful for clinicians. Women also wanted counselling or support lines to be available and advertised in the clinic and included in the invitation letters. Some women wanted control over when the invitation letters were sent to them to avoid upset at specific times such as Christmas. They also wanted the option to defer receiving letters for the present.

Position, procedure and environment

Ten women felt that a less clinical environment would be preferable and if one could "have pictures ... so that you actually see someone, you can see a face and you can see a name" (DPt2) it would make the smear taker familiar to the woman and not a "stranger" prior to the test. Women asked whether the smear could be taken in a different position such as on their side, with different instruments such as a plastic speculum, or whether the test could be different, for example, a blood test. Four women felt that sedation or "numbing" would be the best solution for them.

\section{Time and space}

Time was an important factor with 31\% $(n=38)$ of women commenting on this at least once. Time before, during and after appointments was recommended. Included in this was the idea of more than one appointment; the first to familiarise the woman with her smear taker, the procedure and the instruments without an examination, and the next for the test itself. Some women felt that they were "in a different mental space from everyone around" (Pt21) them and suggested a dedicated clinic for women who have been abused or a private area to regroup after the test and deal with the impact of the emotions that may have been stirred up. Waiting around for their appointment also caused anxiety, so there was a recommendation for a set appointment time without any waiting.

\section{Discussion}

It has been hypothesised that victims of sexual abuse adopt a number of coping strategies to deal with the trauma. $^{38}$ Included in these are behavioural approaches involving actions to reduce the stressful effects of a situation, for example, when having cervical screening. It has been suggested that a gynaecological examination stimulates the conditioned responses of victims of childhood sexual abuse. ${ }^{34}$ The women who participated in this study supported this by reporting the triggering of memories and responses such as dissociation, depression, self-harm, emotional 
pain, fear and anxiety and feelings of sexual victimisation.

Avoidance as a means of protecting oneself from threat is another strategy adopted by this population in which only $48.5 \%$ of those eligible had been screened at least once in the previous 5 years. ${ }^{4}$ Avoidance has been shown to be especially likely if earlier experiences of gynaecological examination have been negative. ${ }^{26} 32$ This is compounded when a woman has been abused. ${ }^{29}$ A history of abuse also correlates with a later stage of diagnosis of cancer in women. ${ }^{18}$ All these factors could have long-term consequences for the health of this population.

The participants in this study recognised the importance of communication between a woman and the smear taker. They mentioned sensitivity, respect, trust and sharing control. A woman should consent to the procedure with an agreement that should she wish to halt the procedure, this would be respected. Addressing the power disparity between woman and smear taker by sharing control was emphasised. This may happen with the woman having choice, not just with regard to the gender of the smear taker or the presence of a chaperone. This trust would extend to the woman being able to curtail the examination and to return when she felt better prepared to cope with the test.

Difficulties with disclosure of a history of sexual abuse are of concern; in particular the inability to verbalise the cause of distress can lead to feelings of being "trapped". Women need support to disclose in order to address these problems. ${ }^{12} 39$ The suggestions made by respondents to deal with this often required minimal verbalisation by the woman herself. The health care provider should ask the questions in a way that requires simple yes or no answers.

Some of the barriers to screening are very closely tied in with the mechanics of the process of taking a smear test. Although there were some practical suggestions, such as lying on the side rather than the back, or self-testing, many of the parallels with abuse are difficult to overcome. Having health care providers with special knowledge of abuse and the effects it can have on women was recommended. Counselling and support should be available, as should the prospect of more than one appointment as part of the process of ensuring that the woman who has been abused can undergo regular screening.

Future cervical screening research with women who have been sexually abused could usefully look at the acceptability of self-sampling. Self-sampling for HPV has been shown to be acceptable to a number of general populations of women and has comparable specificity and sensitivity to cervical cytology in trials. $^{40}$

\section{Study limitations}

This was a small exploratory study where the depth of qualitative data collected could have been enhanced if more discussion groups had taken place. Understandably, however, the women were reluctant to participate. The representativeness of the sample is likely to have been affected by the use of a web-based survey, the link to which was advertised on a website primarily targeted at those abused in childhood. The women accessing the website and completing the survey were likely to be those most affected by their abuse. Larger-scale studies that access participants through a variety of different routes are needed to explore the extent to which our findings are generalisable to other groups of women who have been abused.

\section{Conclusions}

This study goes some way toward supporting the idea that women who have experienced sexual abuse are less likely to attend for regular cervical screening. The implications of this study for clinicians, which have come from the recommendations of the women, include the need to establish trust between the heath care provider and the woman. There should be shared control of the process of cervical screening. Clinicians should ensure they have a good knowledge of the impact of sexual abuse and the sensitivity that is necessary to deal with its consequences. Abused women may need help to disclose their abuse history and to be given the time not only to do this but to undergo the cervical screening test itself. Availability of counselling and support should help with longterm outcomes for women who have been exposed to sexual abuse.

Acknowledgements The authors would like to thank the team at NAPAC for their support and in particular Sarah Kelly. The authors' appreciation goes to the women who completed the survey and who took part in the discussion group.

\section{Competing interests None.}

Funding This study was supported by a grant from the Barts CR-UK Centre (BCC) Development Fund and Cancer Research UK Programme Grants (C569/ A10404 and C8162/A10406).

\section{References}

1 Peto J, Gilham C, Fletcher O, et al. The cervical cancer epidemic that screening has prevented in the UK. Lancet 2004;364:249-256.

2 Sasieni P, Adams J, Cuzick J. Benefit of cervical screening at different ages: evidence from the UK audit of screening histories. Br J Cancer 2003;89:88-93.

3 Sasieni P, Castanon A, Louie K. NHSCSP Audit of Invasive Cervical Cancer National Report 2007-2010. NHS Cancer Screening Programmes 2011. http://www.cancerscreening.nhs. uk/cervical/publications/nhscsp-audit-invasive-cervical-cancer201107.pdf [accessed 22 April 2012].

4 The NHS Information Centre. NHS Cervical Screening Programme Statistical Bulletin (England 2010-11) 2011. http:// www.ic.nhs.uk/webfiles/publications/008_Screening/ 
cervscreen1011/Cervical_Bulletin_2010_11_v1_1.pdf [accessed 22 April 2012].

5 Finkelhor D. The international epidemiology of child sexual abuse. Child Abuse Negl 1994;18:409-417.

6 Garcia-Moreno C, Jansen HA, Ellsberg M, et al. Prevalence of intimate partner violence: findings from the WHO multi-country study on women's health and domestic violence. Lancet 2006;368:1260-1269.

7 May-Chahal C, Cawson P. Measuring child maltreatment in the United Kingdom: a study of the prevalence of child abuse and neglect. Child Abuse Negl 2005;29:969-984.

8 Oaksford KL, Frude N. The prevalence and nature of child sexual abuse: evidence from a female university sample in the UK. Child Abuse Review 2001;10:49-59.

9 Pereda N, Guilera G, Forns M, et al. The international epidemiology of child sexual abuse: a continuation of Finkelhor (1994). Child Abuse Negl 2009;33:331-342.

10 Cawson P, Wattam C, Brooker S, et al. Child maltreatment in the United Kingdom: a study of the prevalence of child abuse and neglect. London, UK: NSPCC, 2000;88.

11 Flatley J, Kershaw C, Smith K, et al. Crime in England and Wales, 2009/10. Findings from the British Crime Survey and police recorded crime. Home Office Statistical Bulletin. London, UK: Home Office, 2010.

12 Campbell J, Jones AS, Dienemann J, et al. Intimate partner violence and physical health consequences. Arch Intern Med 2002;162:1157-1163.

13 Coker AL, Patel N, Krishnaswami S, et al. Childhood forced sex and cervical dysplasia among women prison inmates. Violence Against Women 1998;4:595-608.

14 Coker AL, Hopenhayn C, DeSimone CP, et al. Violence against women raises risk of cervical cancer. $J$ Womens Health (Larchmt) 2009;18:1179-1185.

15 Coker AL, Sanderson M, Fadden MK, et al. Intimate partner violence and cervical neoplasia. J Womens Health Gend Based Med 2000;9:1015-1023.

16 Lechner ME, Vogel ME, Garcia-Shelton LM, et al. Self-reported medical problems of adult female survivors of childhood sexual abuse. J Fam Pract 1993;36:633-638.

17 Modesitt SC, Gambrell AC, Cottrill HM, et al. Adverse impact of a history of violence for women with breast, cervical, endometrial, or ovarian cancer. Obstet Gynecol 2006;107:1330-1336.

18 Nurse J. Violence and Health Briefing. England: South East Public Health Group's Information Series. Department of Health, 2006. http://www.sepho.org.uk [Accessed 22 April 2012].

19 Gutman LT, St Claire K, Herman-Giddens ME, et al. Evaluation of sexually abused and nonabused young girls for intravaginal human papillomavirus infection. Am J Dis Child 1992;146:694-699.

20 International Agency for Research on Cancer (IARC). IARC Monographs on the Evaluation of Carcinogenic Risks to Humans - Human Papillomaviruses (Vol. 64). Geneva, Switzerland: World Health Organization Press, 1995.

21 Stanley M. Early age of sexual debut: a risky experience. J Fam Plann Reprod Health Care 2009;35:118-120.
22 Wingood GM, Seth P, DiClemente RJ, et al. Association of sexual abuse with incident high-risk human papillomavirus infection among young African-American women. Sex Transm Dis 2009;36:784-786.

23 Mosack KE, Randolph ME, Dickson-Gomez J, et al. Sexual risk-taking among high-risk urban women with and without histories of childhood sexual abuse: mediating effects of contextual factors. J Child Sex Abus 2010;19:43-61.

24 Springs FE, Friedrich WN. Health risk behaviors and medical sequelae of childhood sexual abuse. Mayo Clin Proc 1992;67:527-532.

25 Young TK, Katz A. Survivors of sexual abuse: clinical, lifestyle and reproductive consequences. CMAJ 1998;159:329-334.

26 Oscarsson MG, Benzein EG, Wijma BE. Reasons for non-attendance at cervical screening as reported by non-attendees in Sweden. J Psychosom Obstet Gynaecol 2008;29:23-31.

27 Waller J, Bartoszek M, Marlow L, et al. Barriers to cervical cancer screening attendance in England: a population-based survey. J Med Screen 2009;16:199-204.

28 Ackerson K. A history of interpersonal trauma and the gynecological exam. Qual Health Res 2011;22:679-688.

29 Ackerson K, Pohl J, Low LK. Personal influencing factors associated with pap smear testing and cervical cancer. Policy Polit Nurs Pract 2008;9:50-60.

30 Farley M, Golding JM, Minkoff JR. Is a history of trauma associated with a reduced likelihood of cervical cancer screening? J Fam Pract 2002;51:827-831.

31 Harsanyi A, Mott S, Kendall S, et al. The impact of a history of child sexual assault on women's decisions and experiences of cervical screening. Aust Fam Physician 2003;32:761-762.

32 Leeners B, Stiller R, Block E, et al. Effect of childhood sexual abuse on gynecologic care as an adult. Psychosomatics 2007;48:385-393.

33 Havig K. The health care experiences of adult survivors of child sexual abuse - a systematic review of evidence on sensitive practice. Trauma Violence Abuse 2008;9:19-33.

34 Robohm JS, Buttenheim M. The gynecological care experience of adult survivors of childhood sexual abuse: a preliminary investigation. Women Health 1996;24:59-75.

35 Stalker CA, Russell BD, Teram E, et al. Providing dental care to survivors of childhood sexual abuse: treatment considerations for the practitioner. J Am Dent Assoc 2005;136:1277-1281.

36 Joffe H, Yardley L. Content and thematic analysis. In: Marks DF, Yardley L (eds). Research Methods for Clinical and Health Psychology. London, UK: Sage Publications, 2003;56-68.

37 Viera AJ, Garrett JM. Understanding interobserver agreement: the kappa statistic. Fam Med 2005;37:360-363.

38 Walsh K, Fortier MA, DiLillo D. Adult coping with childhood sexual abuse: a theoretical and empirical review. Aggression Violent Behav 2010;15:1-13.

39 Bergmark K, Avall-Lundqvist E, Dickman PW, et al. Synergy between sexual abuse and cervical cancer in causing sexual dysfunction. J Sex Marital Ther 2005;31:361-383.

40 Gravitt PE, Belinson JL, Salmeron J, et al. Looking ahead: a case for human papillomavirus testing of self-sampled vaginal specimens as a cervical cancer screening strategy. Int J Cancer 2011;129:517-527. 